\title{
Forecasting the Monthly Rediscounting Rate in the Philippines
}

\author{
Renato E. Apa-ap* \\ Department of Mathematics and Statistics, Polytechnic University of the Philippines, \\ College of Science, Philippines; r_apaap@yahoo.com/reapa-ap@pup.edu.ph
}

\begin{abstract}
Objective: To develop a best model that can forecast the monthly rediscounting rate in the Philippines. Methods/Statistical Analysis: The researcher utilized the numbers from the certified metadata of the BankoSentral ng Pilipinas (BSP) from January 2009 to December 2015 to shape a forecasting model using the modern forecasting method under time series analysis specifically the Box-Jenkins Procedure. For accurateness of calculations, the researcher employs the use of Statistical Software. Furthermore, the researcher sought to find the finest model using the said forecasting scheme from January 2015 to December 2018. Findings: The results show that the series is persistent at a 4\% rate from February 2010 to February 2011 while it slightly reduced over eight more months. However, another constancy in the monthly Philippine Rediscounting rate happened from November 2012 to October 2013 having a rate of $3.5 \%$. Moreover, after such constancy the monthly Philippine rediscounting rate continued to increase until December 2015. After the testing the assumptions and diagnostic test of model adequacy, the researcher finally creates a best model that can predict the future values of rediscount rate in the Philippines based on the evaluation criteria in selecting the best model. The "best" model for the monthly Philippine rediscounting rate in terms of its significant factors IR (Inflation Rate), MMR (Money-Market Rate), TBR (Treasury Bill Rate) and PDR (Peso-Dollar Rate) is Monthly Rediscounting Rate (Predicted) $_{1}=0.096$ (IR) $0.186(\mathrm{MMR})+0.310(\mathrm{TBR})+0.09(\mathrm{PDR})$. This model building can help the government to create a strategy or system to maintain price stability in the country and help the countrymen to access the basic needs for their everyday life and can be applied to pact with balance-of-payments deficits so as to regulate international movements of capital. Applications/Improvements: Outcome from this study can be used as a monetary tool of the BSP to regulate the level of liquidity in the system. Adding observations from the previous series of the monthly Philippine rediscounting rate may help in discovering a better model in forecasting.
\end{abstract}

Keywords: Forecasting, Monthly, Philippines, Rate, Rediscounting

\section{Introduction}

Currently, most of the people in the Philippines are experiencing skirmish of life in terms of all phases. It covers the financial matter and everyone doing all the best to have a better life. Due to shortage, most of the individual is looking for a big discount for them to save money and as well as different resources. In relative to banks, discount is still applicable for some credits and other matter.
Likewise, a bank professional explicates that the rediscount capability allows banks to take out finances from the BSP to meet short-term liquidity desires with clients' promissory notes as warranty. Broken down, loan acquisitions for the period include $79 \%$ for commercial credits and $5.9 \%$ went to agricultural and industrial credits. The remaining $15.1 \%$ went to other credits composed of perpetual working capital (4.6\%), other services (4.3\%), investment expenditures $(5.1 \%)$, and housing (1.1\%), the BSP said. On the other hand, one 
universal bank and one saving bank tapped the central bank's dollar-denominated facility in 2014 and availed of a total of $\$ 10$ million in loans during the period, which the BSP said profited three exporters. This total was down by $90.9 \%$ from the $\$ 109.4$ million recorded in $2013^{1}$.

Rediscount is just another process of discounting a short-range negotiable debt instrument for a second time. Banks may rediscount these short-array debt sanctuaries to support the crusade of a market that has a high demand for loans. When there is low flexibility in the market, banks can create cash by rediscounting shortterm securities. A central bank's discount capacity is often called a discount window. The term comes from the days when a bank clerk would go to a window at the central bank to rediscount a company's securities ${ }^{2}$.

In ${ }^{3}$ hassled out that on Section 81 of Republic Act (R.A.) No. 7653, similarly known as the New Central Bank Act, provides that the rediscounts, discounts, loans and advances, which BSP is sanctioned to encompass to banking establishments, shall be used to influence the volume of credit unswerving with its objective of maintaining amount stability. During periods of inflation, the BSP shall limit the loans it extends to banks.

Rediscount rate originates in 30, 90, 180 and 360-day maturities. In line with this, these distinct maturities are affected by quite a few aspects by which together with the other gauges of the overall economy reveal the exact credit facility that is computed through the rediscounting rate.

In ${ }^{4}$ considers the following possible factors that influence the monthly Philippine rediscounting rate as follows: Inflation Rate, Money Market Rate, Treasury Bill Rate, Saving Deposit Rate and Peso-Dollar Rate. Inflation Rate is measured by the buyer price index as it reflects the annual percentage change in the cost to the typical consumer of acquiring a basket of possessions and services that may be fixed or changed at specific intervals, such as yearly. Money Market Rate is used by various financial institutions as a means for borrowing and lending in the short term, from several days to just under a year where a segment of the financial market in which financial instruments with high liquidity and very short maturities are traded. The money market is used by a wide array of participants, from a company raising money by selling commercial study into the market to an investor purchasing CDs as a safe place to park money in the short term.
Treasury Bill Rates are parroted either by their crop rate, which is the discount, or by their price based on 100 points per unit. Those Treasury Bills that matures in less than 91-days are called Cash Management Bills (example: 35-day and 42-day). There are three moods of Treasury Bills: 91 days, 182 days and 364days Bills respectively. The number of days is based on the worldwide practice around the world of ensuring that the bills matured on a business day. Savings Deposit Rate comes in moods of short, medium and long-term as well as all maturities and are obtained from home-grown banks, subsidiaries of foreign banks and foreign banks. It is consequent as the proportion of interest expense on peso deposits of reporting commercial banks to the total outstanding level of these deposits. Based on monthly submissions by local banks, subsidiaries of foreign banks and foreign banks itself of interest expense, regular outstanding savings deposits and WAIR. Computed as the annual percentage equivalent of banks' actual monthly interest expense on their peso-denominated savings deposits to the total outstanding levels of their peso-denominated savings deposits. The Philippine Peso-US Dollar exchange rate denotes to the official spot reference exchange rate for the Philippine Peso with the US Dollar. The BangkoSentral ng Pilipinas (BSP) accepts a without restrictions floating exchange rate regime. On a daily basis a Reference Exchange Rate Bulletin (RERB) is released to the general public to serve as a guide on the prevailing spot exchange rates in the international and domestic currency markets.

In view from the said reports, the researcher plans to develop a model in estimating the monthly rediscounting rate in the Philippines using Box Jenkins statistical tool from January 2015 to December 2018. The model can be useful for the government to create policy for maintaining price stability and help the countrymen to access the basic needs for everyday life.

\subsection{Objective of the Study}

Using time series analysis, this research aims to develop a best forecasting model that can predict the monthly Philippine Rediscounting Rate by means of the Seasonal Autoregressive Integrated Moving Average(SARIMA) with Box-Jenkins approach.

\subsection{Statement of the Problem}

Specifically, this research may seek to answer the following questions: 
1. What is the behavior of the monthly Philippine Rediscounting Rate?

2. Is there any seasonality in the monthly Philippine rediscounting rate across months? If yes, what is the pattern of seasonality?

3. What is the best-fitted time series model for the monthly Philippine rediscounting rate from January 2009 to December 2015?

4. What are the prediction values of the monthly Philippine rediscounting rate for January 2016 onwards?

5. What is the best model to forecast the monthly Philippine Rediscounting Rate?

\subsection{Scope and limitation}

The researcher's data applied in this research came from the monthly records of official metadata of the BSP from January 2009 to December 2015. From these data, the researcher builds a model that will be useful to predict monthly rediscounting rate of the Philippines for the next 5 years.

\subsection{Significance of the Study}

Rediscounting is one of the monetary instruments of the BSP to control the level of fluidity in the system. The model developed will be a guide of debtors or even investors in obtaining loans from a bank.

\subsection{Research Paradigm}

\section{Methodology}

The researcher utilized secondary data collected from the record keeping statistical agency, the BSP record on the monthly rediscounting rate of the Philippines, were exploited in building a mathematical model done by advanced statistical tool SARIMA through the use of Box-Jenkins approach in modeling with the assistance of Statistical software for accuracy of computations.

This statistical tool in modeling and forecasting permits the researcher to establish association of the constraints under study. In addition, this study customizes time series analysis statistical approach to realize its objective. Time series analysis ponders that data points taken over period may have a core structure that should be accounted for and it includes methods for analyzing time series data in order

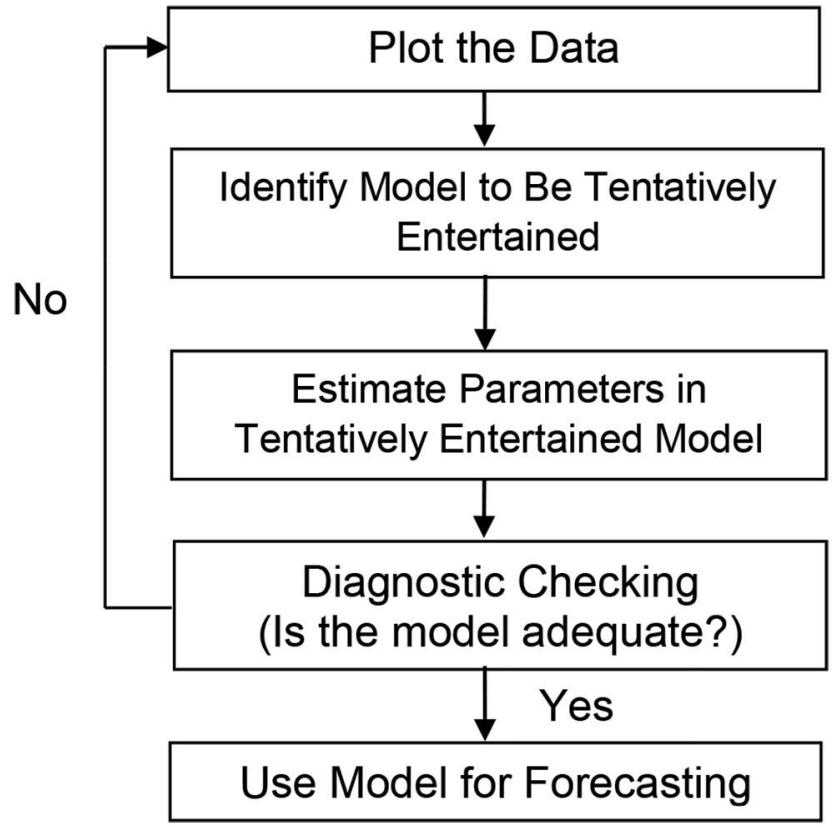

to extract meaningful statistics and other characteristics of the data. Time series forecasting on the other hand, is the usage of a model to predict future values based on past observations. Furthermore, another statistical tool applied is the regression analysis. The Regression analysis is frequently employed to test models that the existing values of one or more independent time series affect the existing value of another time series.

\subsection{Box-Jenkins Methodology}

The Box-Jenkins approach 5 in modeling and forecasting consists of three phases, which are performed iteratively depending upon the suitability of fit of the preliminary identified model for engagement of the time series data. These stages are performed generally on the class models provided by the auto-regressive integrated moving average (ARIMA) process. The three stages are model assortment, restriction estimation, and diagnostic inspection.

To specify the ARIMA model ${ }^{6}$, one must first take the variance of the dependent variable, if necessary, to account for the order of integration, second describe the operational regression model (dependent variables and regressors) and then add any Autoregressive (AR) or Moving Average (MA) terms.

Autocorrelation (ACF) and Partial Autocorrelation Functions (PACF) were employed by the researcher to obtain the correlation of a time series data with previous and future values using the statistical software for the researcher to identify the order of processes in ARIMA 
modeling. These ACF and PACF are plotted graphically into the correlogram plots for visual evaluation. The ACF is a plot or graph of the autocorrelations between the data points in a time series and the key statistic in time series analysis. On other point, ACF is the correlation of the time series with itself, lagged by a certain number of periods

In ${ }^{7}$ test is a statistical tool which is a nonparametric measure and the counterpart of Analysis of Variance (ANOVA) in parametric measures used for comparing samples from two or more independent groups whose data categorized as nominal or ordinal. This test does not make assumptions about normality; however, it assumes that the observations in each group come from populations with the same shape of distribution. The null hypothesis of this study states that all months (or quarters, respectively) have the same mean.

The test is calculated for the final estimation of the unmodified Seasonal-Irregular component from which $k$ samples $A_{j}$ are derived ( $k=12$ for monthly series and $k=4$ for quarterly series) of size $n_{1}, n_{2}, \ldots n_{k}$ respectively.

Unit Root Test is also applied in this study to diagnose more if the time series is stationary or not. Furthermore, the researcher used Augmented Dickey-Fuller test statistics for unit root test which is more powerful than the usual Dickey-Fuller test. The Augmented DickeyFuller test is an improved Dickey-Fuller test, derived from the regression model ${ }^{8}$.

In general, Autoregressive Integrated Moving Average (ARIMA) Model was used to structure the time series data for generating forecasting model together with its key components, the AR and MA processes to further strengthen the model.

Moving Average is a commonly used indicator in technical analysis that helps even out price action by filtering out the "noise" from random price fluctuations. MA is a trend-following or lagging indicator because it is based on past prices.

For further diagnostics of the model, the Ljung-Box test ${ }^{9}$ was also explored which is another type of statistical tool that test whether any of the group of autocorrelations of a time series are different from zero. Instead of testing arbitrariness at each distinct lag, it tests the «overall» randomness based on a number of lags, and is therefore a hybrid test.

Another is the Box-Pierce test $t^{10}$ which is associated to Ljung-Box test which designates that if residuals are white noise, the Q-statistic trails a chi-square distribution with $(\mathrm{h}-\mathrm{m})$ degrees of freedom. Considering that if a model is fitted, then $m$ is the number of parameters. However, no model is fitted here, so our $m=0$. If each $r_{k}$ value is close to zero, then $Q$ will be very small; otherwise, if some $r_{k}$ values are large, either negatively or positively, then $\mathrm{Q}$ will be relatively large. $\mathrm{Q}$ will be compared to the chi-square distribution, just like any other test of significance.

As a rule of thumb, the model was subject to forecasting accuracy measure which is vital factor when defining among forecasting alternatives for appropriateness. Accuracy measure is based on the historical error performance of a forecast. The best fit model was chosen based on the different measures of forecasting accuracy or diagnostic test indicators generated from the software such as Mean Absolute Percentage Error (MAPE) and Root Mean Squared Error (RMSE) ${ }^{11}$.

\section{Results and Discussion}

Rediscounting also allows the central bank to normalize the amount of money circulating in the financial system. However, for the present Philippine economic system, this forecasted series shown in the study should not reflect the exact series that will be generated for the true date. Therefore, the increase in the monthly Philippine rediscounting rate for 2016 will allow the central bank to control the amount of money circulating in the financial system.

Answering the objectives of this study, the researcher concludes the following:

1. The trend of the monthly Philippine rediscounting rate is fluctuating over years. For a term of one year, the series is constant at a 4\% rate from February 2010 to February 2011 while it slightly decreased over eight more months. However, the raw series is not normal. Thus, the series is log-transformed.

2. There is no evidence of seasonality in the monthly Philippine rediscounting rate.

3. $\mathrm{MA}(3)$ is the best-fitted time series model of the monthly Philippine rediscounting rate from January 2009 to December 2015.

4. The monthly rediscounting rate of the Philippines will decrease in the first four months of 2016. 
5. The "best" MLR model for the monthly Philippine rediscounting rate in terms of its significant factors is:

$$
\hat{Y}=0.096 I R-0.186 M M R+0.310 T B R+0.091 P D R
$$

Figure 1 shows the behavior of Rediscounting Rate in the Philippines presented monthly every year. As we can have gleaned from the figure, that most of the time every year, the month of July and August have a decreasing behavior. Additionally, the highest growth rate which is $16.76 \%$ was observed on the month of April on the year 2014-2015.

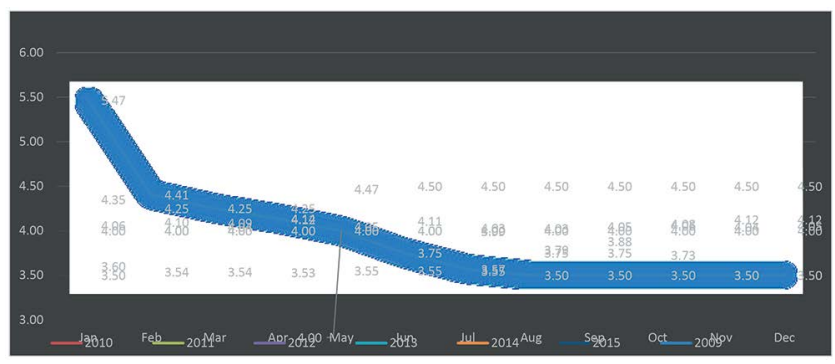

Figure 1. Monthly Philippine rediscounting rate from 2009-2015.

The Table 1 shows the Augmented Dickey Fuller (ADF) test result for identifying whether the data is stationary or not. Based on the table, the computed p-value of ADF test which is equal to 0.0002 as manifested on the table, lead to the decision that there is sufficient evidence to reject the null hypothesis. This further indicates that the given data does not have a unit root or simply the data is stationary.

Table 1. Augmented Dickey-Fuller unit root test of the monthly Philippine rediscounting rate from 2009-2015

\begin{tabular}{|c|c|c|c|}
\hline $\begin{array}{l}\text { Null Hypotl } \\
\text { Exogenous: } \\
\text { Lag Length: }\end{array}$ & $\begin{array}{l}\text { is: RATE has } \\
\text { nstant } \\
\text { Automatic }\end{array}$ & $\begin{array}{l}\text { a unit root } \\
\text { based on SIC }\end{array}$ & xlag=11) \\
\hline & & t-Statistics & Prob.* \\
\hline $\begin{array}{l}\text { Augmented } \\
\text { test statistic }\end{array}$ & ckey-Fuller & -4.755872 & 0.0002 \\
\hline & $1 \%$ level & -3.511262 & \\
\hline Test critical & $5 \%$ level & -2.896779 & \\
\hline & $10 \%$ level & -2.585626 & \\
\hline${ }^{*}$ Mackinno & 1996) one-sic & ed p-values & \\
\hline
\end{tabular}

From the Figure 2, it shows the realization of Rediscounting Rate, Histogram and Summary Statistics of the said series from January 2009 to December 2015. It can be observed that for a term of one year, the series is constant at a $4 \%$ rate from February 2010 to February 2011 while it slightly decreased over eight more months. However, another constancy in the monthly Philippine Rediscounting rate happened from November 2012 to October 2013 having a rate of $3.5 \%$. Moreover, after such constancy the monthly Philippine rediscounting rate continued to increase until December 2015. For the results of Jarque-Bera statistics, the distribution is not normal since there is sufficient evidence to reject the null hypothesis, but the series is normally distributed after obtaining a p-value of near zero which is less than 0.05 level of significance. Also, the series is positively skewed and is leptokurtic after obtaining values for skewness and kurtosis of 0.928194 and 5.159460 respectively.
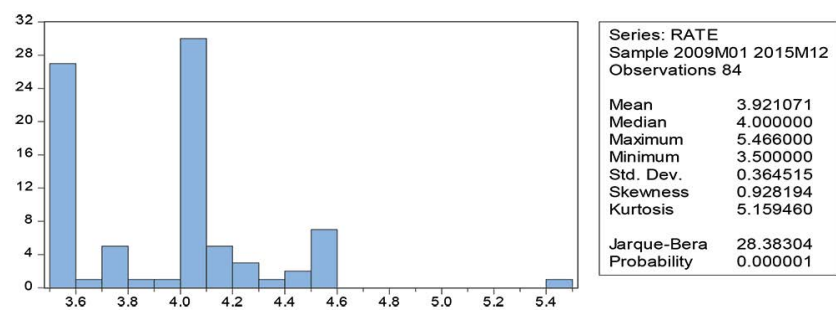

Figure 2. Trend and distribution of the monthly Philippine rediscounting rate.

Table 2 shows the model identification process based on AIC from the monthly working data from 2009 to 2015 of Philippine Rediscounting Rate. It is found that the best model to forecast the monthly is ARIMA $(2,1,0)(1,0,0)^{\underline{12}}$ with drift as manifested on its values. It obtained a lowest AIC which is considered as a valid model.

Figure 3 shows the graph of the residual plot for the best model created. It further shows that the variance of the error term are seems to be constant. It is also noticeable that the average of the residual is equal to -0.0138897 which is approximately equal to zero.

Both Table 3 and Figure 4 shows the residual analysis in identifying the independency of error term for Autoregressive Conditional Heteroskedasticity (ARCH). Since the computed p-value Box-Ljung test is equal to 0.9815 which is greater than the assign alpha level of $5 \%$, hence statistically there is a sufficient evidence to say that the error term is independent.

Table 4 portrays the model selection criteria and forecasting accuracy measures of the candidates for "best" time series model of the monthly Philippine rediscounting rate. The "best" model should have the highest value of $\mathrm{R}^{2}$ 
Table 2. Estimated model based on the Akaike Information Criterion (AIC)

\begin{tabular}{|c|c|c|c|c|}
\hline \multicolumn{5}{|c|}{ Model AIC } \\
\hline $\operatorname{ARIMA}(2,1,2)$ & $(1,0,1)[12]$ & with drift & & $\operatorname{Inf}$ \\
\hline $\operatorname{ARIMA}(0,1,0)$ & with drift & & -51.2241 & \\
\hline $\operatorname{ARIMA}(1,1,0)$ & $(1,0,0)[12]$ & with drift & & -69.82292 \\
\hline $\operatorname{ARIMA}(0,1,1)$ & $(0,1,1)[12]$ & with drift & & -68.13935 \\
\hline $\operatorname{ARIMA}(0,1,0)$ & & & -52.17606 & \\
\hline ARIMA $(1,1,0)$ & With drift & & -57.84489 & \\
\hline $\operatorname{ARIMA}(1,1,0)$ & $(2,0,0)[12]$ & with drift & & -69.38948 \\
\hline ARIMA $(1,1,0)$ & $(1,0,1)[12]$ & with drift & & -69.18461 \\
\hline $\operatorname{ARIMA}(1,1,0)$ & $(2,0,1)[12]$ & with drift & & -67.40384 \\
\hline ARIMA $(2,1,0)$ & $(1,0,0)[12]$ & with drift & & -63.32484 \\
\hline $\operatorname{ARIMA}(2,1,1)$ & $(1,0,0)[12]$ & with drift & & -70.27989 \\
\hline $\operatorname{ARIMA}(3,1,1)$ & $(1,0,0)[12]$ & with drift & & -69.93796 \\
\hline $\operatorname{ARIMA}(2,1,0)$ & $(1,0,0)[12]$ & with drift & & -68.07009 \\
\hline $\operatorname{ARIMA}(2,1,0)$ & $(1,0,0)[12]$ & & & -71.3404 \\
\hline $\operatorname{ARIMA}(2,1,0)$ & & & -58.45965 & \\
\hline $\operatorname{ARIMA}(2,1,0)$ & $(2,0,0)[12]$ & & & -70.12792 \\
\hline $\operatorname{ARIMA}(2,1,0)$ & $(1,0,1)[12]$ & & & -69.9823 \\
\hline ARIMA $(1,1,0)$ & $(2,0,1)[12]$ & & & -68.3065 \\
\hline ARIMA $(3,1,0)$ & $(1,0,0)[12]$ & & & -70.76444 \\
\hline $\operatorname{ARIMA}(2,1,1)$ & $(1,0,0)[12]$ & & & -70.41219 \\
\hline $\operatorname{ARIMA}(3,1,1)$ & $(1,0,0)[12]$ & & & -71.2573 \\
\hline $\operatorname{ARIMA}(3,1,1)$ & $(1,0,0)[12]$ & & & -69.40281 \\
\hline
\end{tabular}

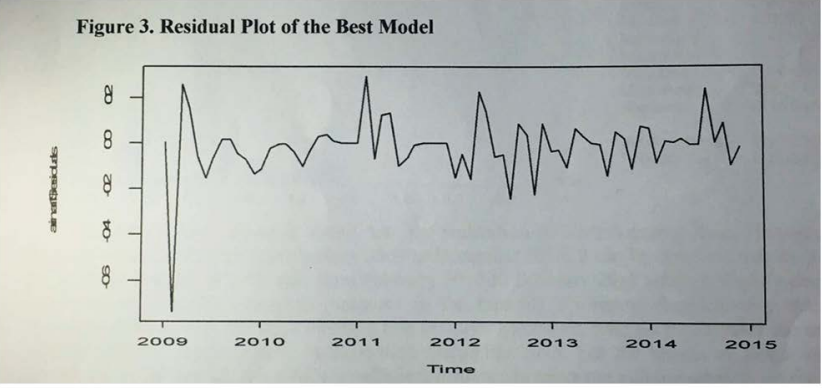

Figure 3. Residual plot of the best model

Table 3. Independency of Error Term for Autoregressive Conditional Heteroskedasticity (ARCH) (Formal way)

\begin{tabular}{|c|c|}
\hline \multicolumn{2}{|c|}{ Box-Ljung test } \\
\hline X-squared & 9.1194 \\
\hline $\mathrm{df}$ & 20 \\
\hline $\mathrm{p}$-value & 0.9815 \\
\hline
\end{tabular}

and lowest values of AIC and SBC for the model selection criteria and also lowest values for the RMSE, MAE and MAPE for the forecasting accuracy measures.

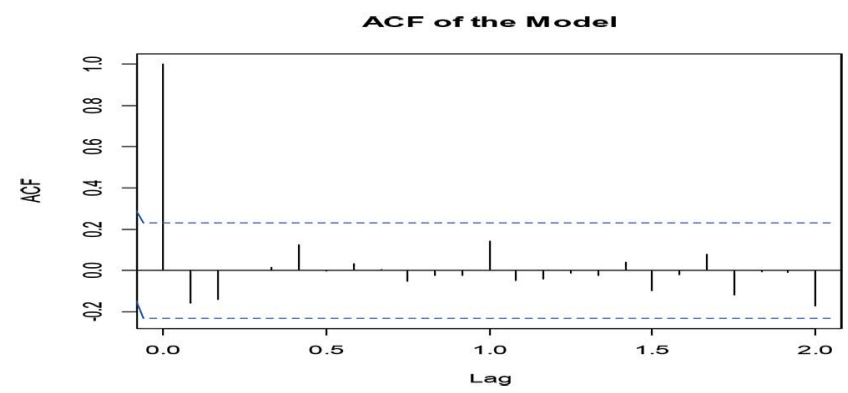

Figure 4. Independency of Error Term Autoregressive Conditional Heteroskedasticity (ARCH) (Informalway).

The results only showed that $\mathrm{MA}(3)$ got the highest value of $\mathrm{R}^{2}$ and lowest values of AIC and SBC for the model selection criteria and also lowest values for the RMSE, 
Table 4. Model selection criteria and forecasting accuracy measures of the candidates for "Best" time series model of the monthly Philippine rediscounting rate

\begin{tabular}{|c|c|c|c|c|c|c|c|c|c|c|}
\hline \multirow{3}{*}{ MODEL } & \multicolumn{10}{|c|}{ FORECASTING } \\
\hline & \multirow[b]{2}{*}{$\mathbf{R}^{2}$} & \multirow[b]{2}{*}{ AIC } & \multirow[b]{2}{*}{ SBC } & \multicolumn{3}{|c|}{ Dynamic } & \multicolumn{3}{|c|}{ Static } & \multirow[b]{2}{*}{$\begin{array}{l}\text { Number of } \\
\text { Parameters }\end{array}$} \\
\hline & & & & RMSE & MAE & MAPE & RMSE & MAE & MAPE & \\
\hline $\operatorname{AR}(1)$ & 0.850529 & -4.008036 & -3.949751 & 0.389967 & 0.331223 & 8.477801 & 0.133407 & 0.082916 & 2.084976 & 1 \\
\hline $\begin{array}{c}\text { ARMA } \\
(1.1) \\
\end{array}$ & 0.875109 & -4.163603 & -4.076175 & 0.344002 & 0.304122 & 7.789679 & 0.117602 & 0.083328 & 2.102173 & 2 \\
\hline MA(1) & 0.677486 & -3.066464 & -3.008587 & 0.321192 & 0.275565 & 7.128944 & 0.205375 & 0.172612 & 4.381908 & 1 \\
\hline $\mathrm{MA}(2)$ & 0.807768 & -3.560099 & -3.473284 & 0.3195 & 0.275208 & 7.11415 & 0.156082 & 0.131859 & 3.353785 & 2 \\
\hline MA(3) & 0.866646 & -3.90198 & -3.78623 & 0.315614 & 0.271039 & 7.018083 & 0.129075 & 0.102761 & 2.61376 & 3 \\
\hline MA(4) & 0.789117 & -0.925711 & -0.757049 & 1.736116 & 1.210768 & 20.78122 & 0.879333 & 0.617857 & 10.94713 & 4 \\
\hline
\end{tabular}

MAE and MAPE for the forecasting accuracy measures. Since MA(3) also satisfied all the assumptions of the time series model, it is considered the best-fitted time series model for the monthly Philippine rediscounting rate. Furthermore, since RMSE, MAE and MAPE values are lower in the static forecasting than in dynamic forecasting, then static forecasting is used in forecasting the monthly Philippine rediscounting rate from January 2016 onwards. In $\frac{12}{}$ develop a criteria to measure a model accuracy based on lowest MAE, RMSE, MAPE values and a higher $\mathrm{R}^{2}$. The above diagnostics of Model Building passed the criteria as mention.

Table 5 shows the residual analysis to identify the normality of error terms. Since the computed p-value of Jarque-Bera test is equal to 0.0000 , there is no enough statistical evidence to reject or fail to reject the null hypothesis of the normality of error term. This means that the error term is normally distributed. Based on JarqueBera $^{\text {ss }}$ statistics if the $\mathrm{p}$-value is far from zero it indicates that the data do not follow a normal distribution. In the case above the data obtained a p-value of 0.0000 which signify a normal distribution.

Table 5. Test for normality of error term

\begin{tabular}{|c|c|}
\hline \multicolumn{2}{|c|}{ Jarque-Bera Test } \\
\hline X-squared & 414.23 \\
\hline $\mathrm{df}$ & 2 \\
\hline $\mathrm{p}$-value & 0.0000 \\
\hline
\end{tabular}

As we can have gleaned on the Table 6 and applying the values manifested, the "best" MLR model for the monthly Philippine rediscounting rate in terms of its significant factors is:

Table 6. Final variables of the regression model

\begin{tabular}{|l|c|c|c|}
\hline \multicolumn{1}{|c|}{ Variables } & Coefficient & Std. Error & p-value \\
\hline Constant & 0.087 & 1.019 & 0.932 \\
\hline Inflation Rate(IR) & 0.096 & 0.030 & 0.002 \\
\hline $\begin{array}{l}\text { Money Market } \\
\text { Rate(MMR) }\end{array}$ & -0.186 & 0.060 & 0.003 \\
\hline $\begin{array}{l}\text { Treasury Bill } \\
\text { Rate(TBR) }\end{array}$ & 0.310 & 0.063 & 0.000 \\
\hline $\begin{array}{l}\text { Peso-Dollar } \\
\text { Rate(PDR) }\end{array}$ & 0.091 & 0.027 & 0.001 \\
\hline
\end{tabular}

$$
\hat{Y}=0.096 I R-0.186 M M R+0.310 T B R+0.091 P D R
$$

\section{Conclusions}

Based on the findings and results presented in previous sections, the following conclusions were drawn:

1. The trend of the monthly Philippine rediscounting rate is fluctuating over years. For a term of one year, the series is constant at a $4 \%$ rate from February 2010 to February 2011 while it slightly decreased over eight more months. However, the raw series is not normal. Thus, the series is log-transformed.

2. There is no evidence of seasonality in the monthly Philippine rediscounting rate. 
3. $\mathrm{MA}(3)$ is the best-fitted time series model of the monthly Philippine rediscounting rate from January 2009 to December 2015.

4. The monthly rediscounting rate of the Philippines will decrease in the first four months of 2016.

5. The "best" MLR model for the monthly Philippine rediscounting rate in terms of its significant factors is: $\hat{Y}=0.096 I R-0.186 M M R+0.310 T B R+0.091 P D R$

\section{Recommendations}

From the aforesaid conclusions, the researcher recommends the following:

1. The researcher recommends $\mathrm{MA}(3)$ as the best-fitted time series model of the monthly Philippine rediscounting rate.

2. The researcher also recommends the model, $=$ in predicting the monthly Philippine rediscounting rate in terms of the significant variables stated in this study.

3. Adding observations from the previous series of the monthly Philippine rediscounting rate may help in discovering a better model in forecasting.

4. BangkoSentral ng Pilipinas (BSP) should stabilize funding and economic balance in order to gain progress in the economy by promoting rediscounting rate.

5. The forecasted rediscount rate shall be used to deal with balance-of-payments deficits-that is, to regulate international movements of capital.

\section{References}

1. BSP mulls further increase in rediscount rate [Internet]. [cited 2010]. Available from: https://www.philstar.com/ authors/1097197/lawrence-agcaoili.
2. Glossary of Terms [Internet]. [cited 2015]. Available from: https://www.oecd.org/sti/inno/Frascati-2015-Glossary.pdf.

3. Loan availments from rediscount window drop [Internet]. [cited2015Jan 13].Availablefrom:http://www.bworldonline. com/content.php?section=Finance $\&$ title=loan-availmentsfrom-rediscount-window-drop-\&id=100702.

4. Statistics Metadata Search [Internet]. [cited 2015]. Available from: http://www.bsp.gov.ph/statistics/statsearch0.asp.

5. Time series Analysis [Internet]. [cited 1994]. Available from: https://press.princeton.edu/titles/5386.html.

6. Adams SO, Awujola A, Alumgudu AI. Modeling Nigeria's consumer price index using Arima model. International Journal of Development and Economic Sustainability. 2014; 2(2):37-47.

7. Time Series Analysis [Internet]. [cited 2014]. Available from: http://itfeature.com/tag/time-series-analysis.

8. Unit Root Test and Augmented Dickey-Fuller (ADF) Test [Internet]. [cited 2016]. Available from: http://www.ams. sunysb.edu/ zhu/ams586/UnitRoot_ADF.pdf.

9. Ljung GM, Box GEP. On the measure of a lack of fit in time series models. Biometrika. 1978; 65(2):297-303. https:// doi.org/10.1093/biomet/65.2.297

10. Box GEP, Pierce DA. Distribution of residual autocorrelation in autoregressive-integrated moving average time series models. Journal of the American Statistical Association. 1970; 65(332):1509-26. https://doi.org/10.1080/01621459. 1970.10481180

11. Testing Normality in Time Series [Internet]. [cited 2011 Nov 14]. Available from: https://editorialexpress. com/cgi-bin/conference/download.cgi?db_name=res_ phd_2012\&paper_id=199.

12. Hsu LC, Wang CH. Forecasting integrated circuit output using multivariate grey model and grey relational analysis. Expert Systems with Application. 2009; 36(2):1403-09. https://doi.org/10.1016/j.eswa.2007.11.015

13. Jarque-Bera ALM Test [Internet]. [cited 2017]. Available from: https://reference.wolfram.com/language/ref/ JarqueBeraALMTest.html. 